\title{
Methylation status of the PTEN gene in adenoid cystic carcinoma cells
}

\author{
XIAOPING FAN $^{1 *},{\text { BIN } \mathrm{CHEN}^{2 *}, \text { JUNLI XU }^{1}, \text { HUACHANG ZHANG }}^{1}$, FENG DENG $^{1}$ and XUERONG XIANG ${ }^{1}$ \\ ${ }^{1}$ Department of Stomatology, Periodontics and Oral Medicine, Stomatological Hospital Affiliated to \\ Chongqing University of Medical Science, Chongqing 400015; ${ }^{2}$ Department of Biochemistry and Molecular Biology, \\ Third Military Medical University, Chongqing 400038, P.R. China
}

Received April 9, 2010; Accepted July 13, 2010

DOI: $10.3892 / \mathrm{mmr} .2010 .337$

\begin{abstract}
The tumor suppressor phosphatase and tensin homolog deleted on chromosome 10 (PTEN) is deficient in various types of human tumors due to mutations or epigenetic alterations. PTEN promoter hypermethylation is a major epigenetic silencing mechanism leading to self-repression in these tumors. The present study aimed to investigate whether PTEN promoter methylation is involved in the regulation of the PTEN gene in adenoid cystic carcinoma (ACC) cells. The expression of PTEN in ACC-2 cells was found to be significantly lower than that in normal salivary gland epithelial cells using RT-PCR analysis. The existence of $\mathrm{CpG}$ island methylation in the PETN promoter region in ACC-2 cells was demonstrated by methylation-specific PCR (MSP) analysis and direct sequencing of MSP product. RT-PCR, Western blot analysis and luciferase assay showed that mRNA and protein expression and the promoter activity of PTEN in ACC-2 cells treated with the DNA methylation inhibitor 5-aza-2-deoxycytidine were significantly up-regulated in a time-dependent manner. These results indicate that the hypermethylation of the PTEN promoter region leads to lower expression of PTEN gene in ACC cells, which aids in the development of PTEN as a molecular marker for the early diagnosis of this carcinoma.
\end{abstract}

\section{Introduction}

Salivary adenoid cystic carcinoma (ACC) is one of the most common salivary gland malignancies and the most common

Correspondence to: Dr Xuerong Xiang or Dr Feng Deng, Department of Stomatology, Periodontics and Oral Medicine, Stomatological Hospital Affiliated to Chongqing University of Medical Science, Chongqing 400015, P.R. China

E-mail: cqzxfxp@sina.com and deng63@263.net

${ }^{*}$ Contributed equally

Key words: PTEN, DNA methylation, methylation-specific polymerase chain reaction, 5-aza-2-deoxycytidine cause of oral cancer-related death worldwide. At present, the biological mechanism behind the proliferation, differentiation, invasion and metastasis of salivary adenoid cystic carcinoma remains unclear $(1,2)$. It has been reported that a variety of oncogenes, including c-erbB-2, c-myc, ras and bcl-2, are associated with adenoid cystic carcinoma (3-6). In addition, studies have reported that the tumor suppressor gene p53 is involved in the pathogenesis of salivary adenoid cystic carcinoma. However, increased expression of p53 in salivary adenoid cystic carcinoma was observed in contrast to its reduced expression in many other tumors, which indicated that it does not serve as a diagnostic marker of salivary gland tumors $(7,8)$.

Phosphatase and tensin homolog deleted on chromosome 10 (PTEN), a tumor suppressor that regulates multiple cellular functions including cell growth and survival, differentiation and proliferation, apoptosis, focal adhesion, invasion, migration as well as angiogenesis, is frequently deficient in various tumors due to mutations or epigenetic alterations (9). PTEN promoter hypermethylation is a major epigenetic silencing mechanism leading to low expression in tumors (10). Previous studies have shown that the abnormal expression of PTEN in oral and maxillofacial tumors is related to the occurrence, development and invasion of tumors (11). The high expression of PTEN in normal salivary glands and low expression in adenoid cystic carcinoma has also been observed, but the molecular mechanisms are unclear $(12,13)$.

In this study, we focused on whether PTEN promoter methylation is involved in the regulation of the PTEN gene in adenoid cystic carcinoma cells. The differential expression of PTEN between normal salivary gland epithelial cells and adenoid cystic carcinoma (ACC-2) was observed. Differences in the methylation status of the PTEN promoter region in the two cell lines were then identified, and changes in PTEN expression in ACC-2 cells treated with the DNA methylation inhibitor 5-aza-2-deoxycytidine were analyzed. The results suggest that hypermethylation of the PTEN gene promoter region leads to lower expression of the PTEN gene in adenoid cystic carcinoma cells. This aids in the exploration of the function of PTEN gene methylation status in the pathogenesis of salivary adenoid cystic carcinomas, and in the development of the PTEN gene as a molecular marker for early diagnosis. 


\section{Materials and methods}

Cell lines and culture conditions. Normal salivary gland epithelial cells were grown from salivary gland epithelium harvested from fresh surgical specimens obtained from patients undergoing lobectomy procedures. The mucosal layer was stripped under sterile conditions from the salivary gland, cut into small pieces and placed on a plastic tissue culture plate containing a thin layer of medium. For each experiment, normal salivary gland epithelial cells from a single patient were used. Normal salivary gland epithelial cells were grown in DMEM (Hyclone, Logan, UT, USA) on standard plastic ware (Becton-Dickinson, Bedford, MA, USA) at $37^{\circ} \mathrm{C}$ in a $5 \%$ $\mathrm{CO}_{2}$ atmosphere. The ACC-2 cell lines were obtained from the West China College of Stomatology, Sichuan University, and were routinely maintained in RPMI-1640 supplemented with 10\% FBS. 5-aza-2-deoxycytidine was added to RPMI-1640 containing $10 \%$ serum.

Genomic DNA extraction and bisulfite modification. Genomic DNA was extracted from normal salivary gland epithelial cells and ACC- 2 cell lines using the PureLink ${ }^{\mathrm{TM}}$ Genomic DNA kit (Invitrogen, Carlsbad, CA, USA). DNA $(1 \mu \mathrm{g})$ was denatured with $3 \mathrm{~mol} / \mathrm{l} \mathrm{NaOH}$ at $50^{\circ} \mathrm{C}$ for $10 \mathrm{~min}$ followed by incubation with $3.3 \mathrm{~mol} / \mathrm{l}$ sodium bisulfite and $10 \mathrm{mmol} / \mathrm{l}$ hydroquinone at $55^{\circ} \mathrm{C}$ for $16 \mathrm{~h}$, which converts all unmethylated cytosine residues to uracil. The modified DNA was purified using a NucleoSpin Extract II kit (Macherey-nagel, Dueren, Germany). The eluted DNA was suspended in $25 \mu \mathrm{l} \mathrm{H}_{2} \mathrm{O}$ and stored at $-80^{\circ} \mathrm{C}$ until polymerase chain reaction $(\mathrm{PCR})$.

Methylation-specific polymerase chain reaction. Two primer sets were used to amplify the PTEN promoter region from -2262 to -2242 nucleotides upstream of the translation start site, which incorporated a number of $\mathrm{CpG}$ sites, one specific for the methylated sequence (PTEN-M: left primer 5'-TTA GATAGGTGTTTTTTGGGTTTTT-3'; right primer 5'-CCC CCAAATCTATATCCTCATAATAT-3'), and the other for the unmethylated sequence (PTEN-UM: left primer: 5'-TTAGAT AGGTGCCCTTTGGGCCCTTG-3'; right primer 5'-CCCCCA AATCTGTGTCCTCATGGTGT-3'). The primers used in the present study specifically detect the promoter sequence of the PTEN gene rather than that of the PTEN pseudogene. Polymerase chain reactions for PTEN-UM and PTEN-M were carried out in a $50-\mu l$ volume containing $1 \mathrm{X}$ polymerase chain reaction buffer $\left(15 \mathrm{mmol} / 1 \mathrm{MgCl}_{2}\right)$, a $2.5 \mathrm{mmol} / \mathrm{l}$ mixture of dNTPs, $10 \mathrm{pM}$ of each primer, 5 units HotStart Taq DNA polymerase (Qiagen, Valencia, CA, USA) and 25-50 ng of bisulfite-modified DNA. Amplification was performed in a thermocycler with the following conditions: $94^{\circ} \mathrm{C}$ for $5 \mathrm{~min}$, 38 cycles at $94^{\circ} \mathrm{C}$ for $30 \mathrm{sec}, 60^{\circ} \mathrm{C}$ for $30 \mathrm{sec}$ and $72^{\circ} \mathrm{C}$ for $30 \mathrm{sec}$, followed by extension at $72^{\circ} \mathrm{C}$ for $5 \mathrm{~min}$.

Direct sequence analysis. The product of methylation-specific PCR (MSP) amplification was purified with the Omega DNA gel extraction kit according to the manufacturer's instructions. The recovered DNA fragment was inserted into the pMD18-T vector and then transformed into $E$. coli $\mathrm{DH} 5 \alpha$. The positive clones were screened by restriction enzyme digestion, and then sequenced by Ying-chun (Shanghai, China).

\section{Marker \\ 1 \\ 2}

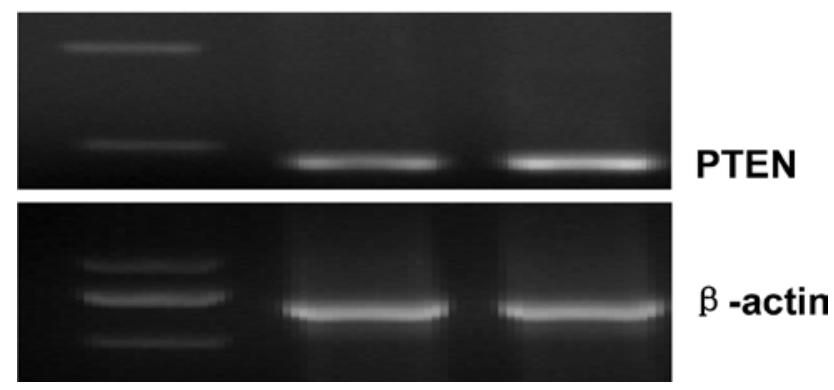

Figure 1. RT-PCR analysis of PTEN in normal salivary gland epithelial cells (lane 1) and ACC-2 cells (lane 2).

Western blot analysis. Whole-cell lysates were prepared in lysis buffer [50 mM HEPES (pH 7.5), $150 \mathrm{mM} \mathrm{NaCl}, 1.5 \mathrm{mM}$ $\mathrm{MgCl}_{2}, 1 \mathrm{mM}$ EDTA, $0.2 \mathrm{mM}$ EGTA, $1 \%$ NP40, 10\% glycerol, $1 \mathrm{mM}$ dithiothreitol, $1 \mathrm{mM}$ phenylmethylsulfonyl fluoride, $20 \mathrm{mM}$ sodium fluoride, $5 \mathrm{mM}$ sodium orthovanadate, $10 \mathrm{mg} /$ $\mathrm{ml}$ aprotinin, $10 \mu \mathrm{g} / \mathrm{ml}$ leupeptin, $2 \mathrm{mg} / \mathrm{ml}$ pepstatin and $1 \mathrm{mM}$ benzamidine]. Lysates were incubated for $20 \mathrm{~min}$ on ice and centrifugated at $12,000 \mathrm{xg}$ for $15 \mathrm{~min}$. The supernatants were collected and the protein concentration was determined with a protein assay kit (Bio-Rad, Hercules, CA, USA). Cell lysates were electrophoresed using SDS-PAGE and then transferred onto a PVDF membrane (Millipore, Billerica, MA, USA). The membranes were immunoblotted overnight at $4^{\circ} \mathrm{C}$ with a rabbit polyclonal antibody against human PTEN (Cell Signaling, Boston, MA, USA) and a goat antibody against $\beta$-actin (Cell Signaling) in Tris-buffered saline containing 5\% non-fat dry milk. Antibody binding was detected using the ECL kit (Amersham Life Sciences, Buckinghamshire, UK) according to the manufacturer's directions.

5-aza-2-deoxycytidine treatment and RT-PCR. The ACC-2 cells were transferred onto a $100-\mathrm{mm}^{3}$ dish. One day later, $10 \mu \mathrm{M}$ 5-aza-2-deoxycytidine was added in RPMI-1640 containing $10 \%$ FBS. The medium was then replaced daily with fresh medium containing 5-aza-2-deoxycytidine. After 24, 48 and $72 \mathrm{~h}$ of treatment, the cells were lysed in RNAiso ${ }^{\mathrm{TM}}$ Plus, and total cellular RNA was extracted. RNA was subjected to electrophoresis ( $20 \mu \mathrm{g} / \mathrm{lane}$ ) on a $1 \%$ agarose gel. Reverse transcription of RNA was carried out in a 10- $\mu$ l volume containing PrimeScript ${ }^{\circledR}$ RTase, 5X PrimeScript ${ }^{\circledR}$ buffer, dNTP Mixture, Oligo dT Primer $(50 \mu \mathrm{M})$, Random 6 mers $(50 \mu \mathrm{M})$, RNase free $\mathrm{H}_{2} \mathrm{O}$ (Qiagen) and 25-50 ng of RNA. Reverse transcription was performed in a thermocycler with the following conditions: $37^{\circ} \mathrm{C}$ for $15 \mathrm{~min}$ and $85^{\circ} \mathrm{C}$ for $15 \mathrm{sec}$. The primers (PTEN-1, left primer: 5'-ACCAGGACCAGAGGAAACCT-3'; right primer: 5'-GCTAGCCTCTGGATTTGACG-3') were used to detect the expression of the PTEN gene. The polymerase chain reaction for PTEN-1 was carried out in a $25-\mu 1$ volume containing $1 \mathrm{X}$ polymerase chain reaction buffer $\left(15 \mathrm{mmol} / 1 \mathrm{MgCl}_{2}\right)$, a $2.5 \mathrm{mmol} / \mathrm{l}$ mixture of dNTPs, $10 \mathrm{pM}$ of each primer, 5 units HotStart Taq DNA polymerase (Qiagen) and 25-50 ng of cDNA. Amplification was performed in a thermocycler with the following conditions: $94^{\circ} \mathrm{C}$ for $5 \mathrm{~min}$, 38 cycles at $94^{\circ} \mathrm{C}$ for $30 \mathrm{sec}, 60^{\circ} \mathrm{C}$ for $30 \mathrm{sec}$ and $72^{\circ} \mathrm{C}$ for $30 \mathrm{sec}$, followed by extension at $72^{\circ} \mathrm{C}$ for $5 \mathrm{~min}$. 


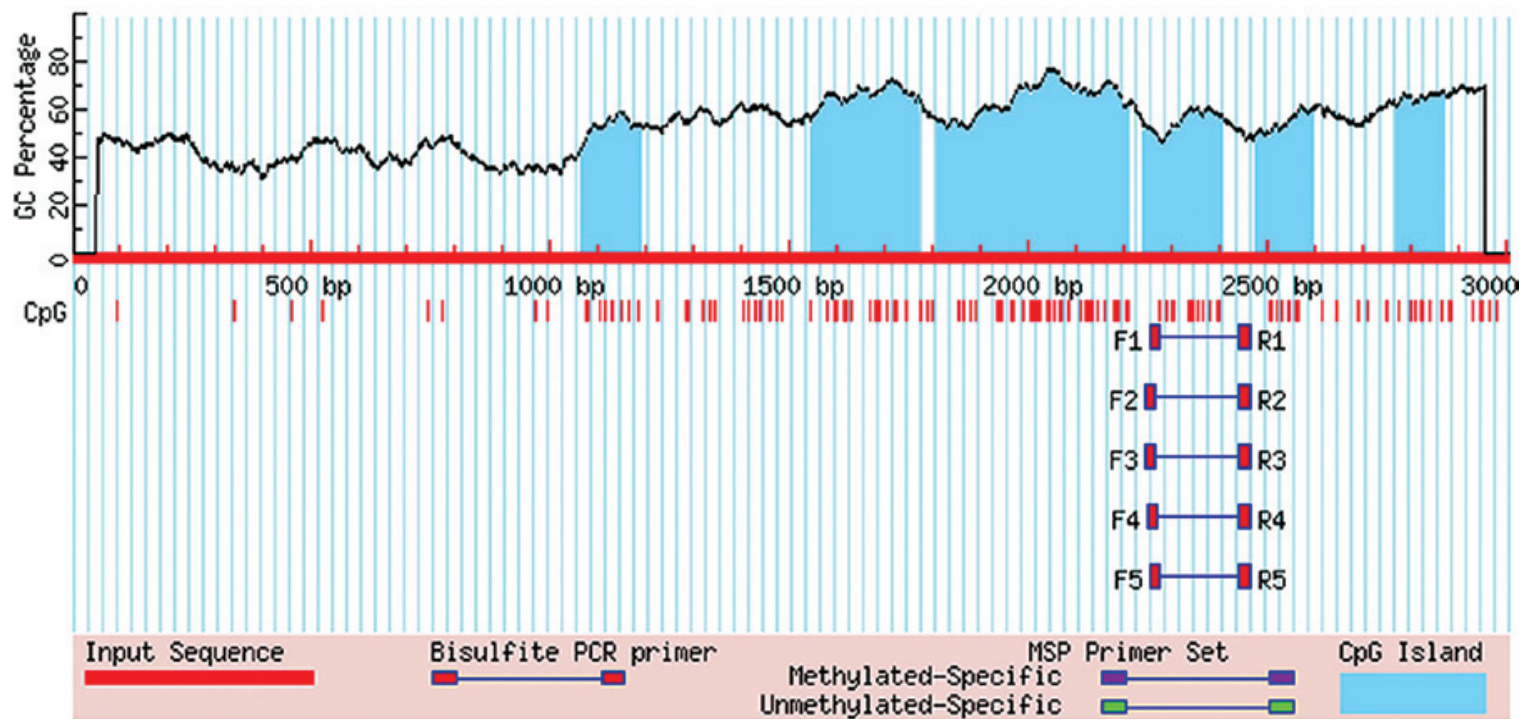

Figure 2. Predicted $\mathrm{CpG}$ islands in the promoter region of PTEN. Using the MethPrimer program, 6 potential CpG islands in the promoter region of PTEN were predicted.

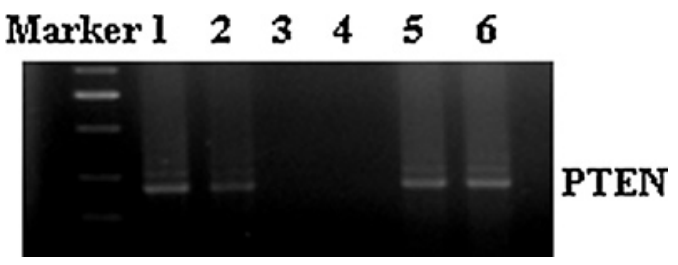

Figure 3. Methylation status of PTEN in normal salivary gland epithelial cells and ACC-2 cells. MSP was performed according to the process described in Materials and methods. The PCR products were amplified using methylation primers in ACC-2 cells (lane 1), non-methylation primers in ACC-2 cells (lane 2), non-bisulfite-modified DNA and methylation primers in ACC-2 cells (lane 3), non-bisulfite-modified DNA and methylation primers in the normal salivary gland epithelial cells (lane 4), methylation primers in the normal salivary gland epithelial cells (lane 5) or non-methylation primers in the normal salivary gland epithelial cells (lane 6).

Construction of PTEN promoter plasmids. DNA fragments of PTEN containing the 5'-flanking region and 5'-untranslated region, as well as the full-length of the PTEN promoter region, were obtained by PCR using the primers 5'-GATAGA TCTGGGTGGGGTGCGGGGTAGGAGTGC-3' and 5'-GAG AAGCTTGCTGCGGCGGCTGCTGGATGGTTG-3'. The fragment was subcloned into the luciferase reporter plasmid pGL3-basic (Promega, Madison, WI, USA) and was digested with $B g l$ II and HindIII restriction enzymes. The positive clones pGL3-PTEN-2927 and -160 were identified by restriction enzyme digestion and DNA sequencing, and aligned with the GenBank databases.

Transient transfection and luciferase assay. ACC-2 cells were seeded into 6 -well plates at a density of $1.5 \times 10^{5}$ cells per well, 1 day before transfection. Transfection was performed with Lipofectamine ${ }^{\mathrm{TM}} 2000$ transfection reagent (Invitrogen) according to the manufacturer's guidelines. The full-length promoter plasmids pGL3-PTEN-2927/-160 (3 $\mu \mathrm{g})$ and $0.1 \mu \mathrm{g}$ of pSV $\beta$-gal were added to each well. After $48 \mathrm{~h}$, the cells were lysed with lysis buffer (Promega). Luciferase activity was measured using the luciferase assay (Promega). $\beta$-gal activity was measured by the $\beta$-galactosidase enzyme assay (Promega). All the luciferase assays were carried out at least in triplicate, and the experiments were repeated three times.

Statistical analysis. Statistically significant differences were assessed using a Student's t-test. $\mathrm{P}<0.05$ was considered to be statistically significant.

\section{Results}

Expression of PTEN in normal salivary gland epithelial cells and ACC-2 cells. RT-PCR analysis showed that the expression of PTEN in the ACC-2 cells was significantly lower than that in the normal salivary gland epithelial cells (Fig. 1).

Prediction of $\mathrm{Cp} G$ islands in the PTEN promoter region. Using the MethPrimerprogram(http://www.urogene.org/methprimer/), the distribution of $\mathrm{CpG}$ islands in the $\sim 3 \mathrm{~kb}$ region upstream of the transcription start site of PTEN was predicted. Six potential $\mathrm{CpG}$ islands were found in the promoter region of PTEN, which were localized from -1190 to $-1064,-1769$ to $-1545,-2208$ to $-1809,-2405$ to -2240 and -2866 to -2766 nucleotides upstream of the translation start site, respectively (Fig. 2).

Methlylation status of PTEN in normal salivary gland epithelial cells and ACC-2 cells. Using the DNA extracted from the normal salivary gland epithelial cells and ACC-2 cells as templates, two primer pairs, the methlyation-specific primer (M) and non-methylation primer (UM), were used to amplify the PTEN promoter region from -2262 to -2242 nucleotides upstream of the translation start site, which incorporated a number of $\mathrm{CpG}$ sites. Two fragments with expected sizes of 221 bp were amplified by MSP or regular RT-PCR (Fig. 3).

The MSP product was subcloned into the $\mathrm{T}$ vector and used for direct sequence analysis. Methylation frequencies of $4.8 \%$ occurred in this region in the ACC- 2 cells. However, no methylation of $\mathrm{CpG}$ sites was found in the same region in the normal salivary gland epithelial cells. 


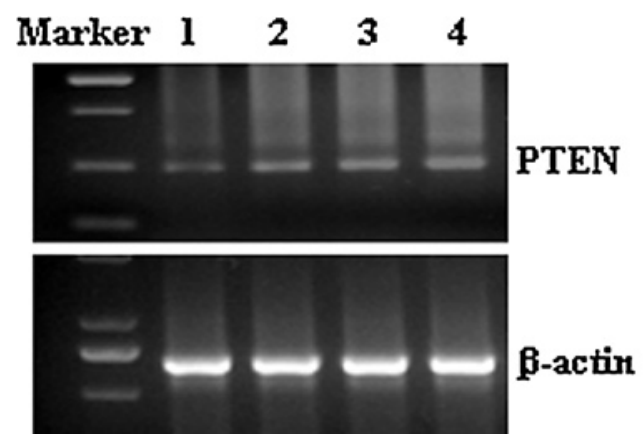

Figure 4. RT-PCR analysis of PTEN mRNA level in ACC-2 cells treated without 5-aza-2-deoxycytidine (lane 1) or with $10 \mu \mathrm{M}$ of 5-aza-2-deoxycytidine for $24 \mathrm{~h}$ (lane 2), $48 \mathrm{~h}$ (lane 3 ) or $72 \mathrm{~h}$ (lane 4).

\section{5-Axa-dc $(10 \mu \mathrm{M})$}

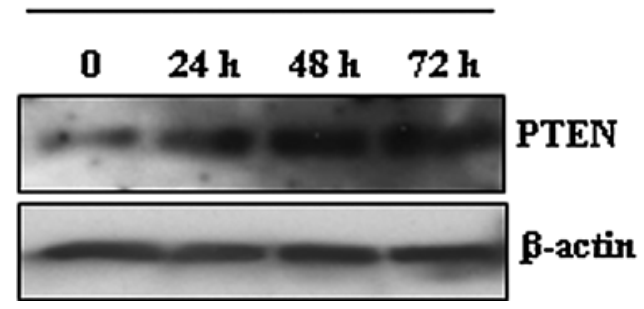

Figure 5. Western blot analysis of PTEN in ACC-2 cells treated with or without 5-aza-2-deoxycytidine for 24,48 or $72 \mathrm{~h}$.

Effect of 5-aza-2-deoxycytidine treatment on PTEN expression in ACC-2 cells. ACC-2 cells were treated without or with $10 \mu \mathrm{M}$ 5-aza-2-deoxycytidine for 24, 48 and $72 \mathrm{~h}$, the RNAs and whole-cell lysates were extracted from the cells and RT-PCR and Western blot analysis were performed. Compared to the control, the levels of mRNA and protein expression in the treated ACC-2 cells were found to be increased in a timedependent manner (Figs. 4 and 5).

Effect of 5-aza-2-deoxycytidine treatment on PTEN promoter activity in ACC-2 cells. ACC-2 cells were transiently transfected with reporter plasmid containing the PTEN promoter, then treated with $10 \mu \mathrm{M}$ 5-aza-2-deoxycytidine for 24,48 and $72 \mathrm{~h}$. Subsequently, the luciferase assay was performed. Compared to the control, the promoter activity of PTEN in the treated ACC-2 cells was found to be increased in a time-dependent manner (Fig. 6), as was the effect of 5-aza2-deoxycytidine treatment on the expression of PTEN in the ACC-2 cells.

\section{Discussion}

As a major tumor suppressor gene, PTEN controls various processes, such as cell cycle progression, cell survival, translation and metabolism. Changes in PTEN expression are associated with the pathogenesis of various tumors. There is evidence to suggest that PTEN expression is much lower in many tumors, such as liver, lung and cervical cancers and oral squamous cell carcinoma, than in their corresponding normal tissues or cells (14-17). PTEN expression is also found to be much lower in adenoid cystic carcinomas than in salivary

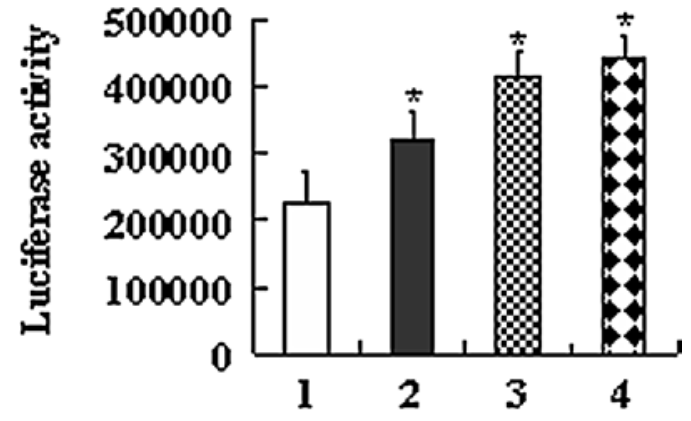

Figure 6. PTEN promoter activity in ACC-2 cells treated with or withou $10 \mu \mathrm{M} 5$-aza-2-deoxycytidine. The PTEN promoter plasmid pGL3-PTEN2927/-160 was transfected into ACC-2 cells. After incubation in the absence (1) or presence of 5-aza-dc for $24 \mathrm{~h}$ (2), $48 \mathrm{~h}$ (3) or $72 \mathrm{~h}$ (4), cells were harvested. Luciferase activity in the cell lysates was measured and expressed as the mean \pm SD of three independent transfection experiments.

glands. Simultaneously, its expression is related to a certain type of organization, but there is no significant correlation between its expression and its degree of differentiation $(12,13)$. This suggests that the inhibition of PTEN transcription may play an important role in the occurrence and development of adenoid cystic carcinoma.

DNA methylation is an important method for controlling the expression of mammalian genes. Although it does not result in changes in the DNA sequence, epigenetic regulation through the chemical modification of the DNA itself controls gene expression at the transcriptional level. The occurrence of tumors is often accompanied by modified patterns of DNA methylation. Therefore, these observable changes of DNA are used as a molecular marker for the early diagnosis of cancer $(18,19)$.

Recent studies have shown that, similar to other tumor suppressor genes, the reduced expression of PTEN in tumor tissue is related to the methylation of its promoter region (10). PTEN expression is lower in adenoid cystic carcinomas than in normal salivary gland epithelial cells, as shown in Fig. 1 and in previous investigations $(12,13)$. However, it is not clear whether the reduced PTEN expression in adenoid cystic carcinoma is associated with the modified methylation status of the PTEN promoter region. Therefore, studies on the expression and methylation status of PTEN in adenoid cystic carcinoma and their relationship are required in order to clarify the pathogenetic mechanisms of adenoid cystic carcinomas.

In the present study, using the MethPrimer program, the distribution of $\mathrm{CpG}$ islands in the promoter region of PTEN was analyzed (Fig. 2) and the methlylation status of $\mathrm{CpG}$ islands in the promoter region of PTEN in the normal salivary gland epithelial cells and ACC-2 cells was identified by MSP. Using methlyation-specific primer or non-methylation primer, two fragment sizes were expected to be contained in the promoter region from -2262 to -2242 nucleotides upstream of the translation start site, incorporating a number of $\mathrm{CpG}$ sites. If these were amplified (Fig. 3), it would indicate the existence of $\mathrm{CpG}$ island methylation in the promoter region of PTEN in adenoid cystic carcinoma. The results of direct sequence analysis of the MSP product showed that there are methylation frequencies of $4.8 \%$ in this region of the ACC-2 cells, but no methylated $\mathrm{CpG}$ sites in the normal salivary gland epithe- 
lial cells. This further suggests that the hypermethylation of the PTEN promoter region is one of the major mechanisms leading to the reduced expression of PTEN in adenoid cystic carcinoma.

In contrast to other genetic changes, such as gene deletion and mutation, epigenetic changes, including DNA methylation in tumors, are reversible (20). Therefore, some key tumor suppressor genes, whose expression is inhibited due to methylation, may be re-activated by specific treatments, such as DNA demethylation. To verify the regulatory role of the hypermethylation of the PTEN promoter region in the expression of PTEN in adenoid cystic carcinoma, ACC-2 cells were treated with the DNA demethylation reagent 5-aza-2-deoxycytidine, which has methyltransferase activity (21), for 24, 48 and $72 \mathrm{~h}$. The results of RT-PCR and Western blot analysis showed that the mRNA levels and protein expression of PTEN in the ACC-2 cells were significantly up-regulated and increased in a time-dependent manner (Figs. 4 and 5). The up-regulation of PTEN expression in the ACC-2 cells was due to the improvement of PTEN gene promoter activity after DNA methylation inhibitor treatment, demonstrated by transient transfection and the luciferase assay (Fig. 6). These results suggest that the hypermethylation of the PNRC promoter region, as an apparent epigenetic change, led to reduced PTEN expression in adenoid cystic carcinoma and was involved in the transcriptional repression of PTEN. This was closely related to the occurrence and development of adenoid cystic carcinoma.

In conclusion, our study demonstrates that the hypermethylation of the PTEN promoter region is one of the major mechanisms leading to reduced expression of PTEN in adenoid cystic carcinomas. This indicates that PTEN is an important candidate gene involved in the pathogenesis of adenoid cystic carcinomas. This study provides a basis for the development of PTEN as a molecular marker for the early diagnosis of adenoid cystic carcinoma.

\section{Acknowledgements}

We are grateful to Dr Zhougui Peng of the Chongqing Key Laboratory of Ophthalmology for the support of our research program. This study was supported by the Foundation of Municipal Health Bureau of Chongqing, China (No. 20092-148).

\section{References}

1. Chandana SR and Conley BA: Salivary gland cancers: current treatments, molecular characteristics and new therapies. Expert Rev Anticancer Ther 8: 645-652, 2008.

2. Dodd RL and Slevin NJ: Salivary gland adenoid cystic carcinoma: a review of chemotherapy and molecular therapies. Oral Oncol 42: 759-769, 2006.

3. Glisson B, Colevas AD, Haddad R, Krane J, El-Naggar A, Kies M, Costello R, Summey C, Arquette M, Langer C, Amrein PC and Posner M: HER2 expression in salivary gland carcinomas: dependence on histological subtype. Clin Cancer Res 10: 944-946, 2004.
4. Sequeiros-Santiago G, García-Carracedo D, Fresno MF, Suarez C, Rodrigo JP and Gonzalez MV: Oncogene amplification pattern in adenoid cystic carcinoma of the salivary glands. Oncol Rep 21: 1215-1222, 2009.

5. An J, Sun JY, Yuan Q, Tian HY, Qiu WL, Guo W and Zhao FK Proteomics analysis of differentially expressed metastasisassociated proteins in adenoid cystic carcinoma cell lines of human salivary gland. Oral Oncol 40: 400-408, 2004.

6. Jia L, Esguerra RL, Tang X, Yin H, Sakamoto K, Okada N and Takagi M: Prognostic value of apoptosis and apoptosisassociated proteins in salivary gland adenoid cystic carcinoma. Pathol 54: 217-723, 2004.

7. Affolter A, Helmbrecht S, Finger S, Hörmann K and Götte K: Altered expression of cell cycle regulators p21, p27, and p53 in tumors of salivary glands and paranasal sinuses. Oncol Rep 13: 1089-1094, 2005

8. Nordkvist A, Röijer E, Bang G, Gustafsson H, Behrendt M, Ryd W, Thoresen S, Donath K and Stenman G: Expression and mutation patterns of p53 in benign and malignant salivary gland tumors. Int J Oncol 16: 477-483, 2000.

9. Renner O, Blanco-Aparicio C and Carnero A: Genetic modelling of the PTEN/AKT pathway in cancer research. Clin Transl Oncol 10: 618-627, 2008.

10. Zhu Y, Wloch A, Wu Q, Peters C, Pagenstecher A, Bertalanffy H and Sure U: Involvement of PTEN promoter methylation in cerebral cavernous malformations. Stroke 40: 820-826, 2009.

11. Mavros A, Hahn M, Wieland I, Koy S, Koufaki ON, Strelocke K, Koch R, Haroske G, Schackert HK and Eckelt U: Infrequent genetic alterations of the tumor suppressor gene PTEN/MMAC1 in squamous cell carcinoma of the oral cavity. J Oral Pathol Med 31: 270-276, 2002

12. Shen L and Sun CF: The expression of PTEN and PKB in salivary adenoid cystic carcinoma and its clinical significance. Shanghai Kou Qiang Yi Xue 14: 159-163, 2005.

13. Zhang B and Sun CF: The expression of tumor suppressor gene PTEN protein and focal adhesion kinase in salivary adenoid cystic carcinoma and its significance. Shanghai Kou Qiang Yi Xue 14: 578-581, 2005.

14. Hu TH, Wang $\mathrm{CC}$, Huang $\mathrm{CC}$, Chen $\mathrm{CL}$, Hung $\mathrm{CH}$, Chen $\mathrm{CH}$, Wang JH, Lu SN, Lee CM, Changchien CS and Tai MH: Downregulation of tumor suppressor gene PTEN, overexpression of p53, plus high proliferating cell nuclear antigen index predict poor patient outcome of hepatocellular carcinoma after resection. Oncol Rep 18: 1417-1426, 2007.

15. Shin KH, Kim JM, Rho KS, Park KH, Oh JE and Min BM Inactivation of the PTEN gene by mutation, exonic deletion, and loss of transcript in human oral squamous cell carcinomas. Int J Oncol 21: 997-1001, 2002.

16. Noro R, Gemma A, Miyanaga A, Kosaihira S, Minegishi Y, Nara M, Kokubo Y, Seike M, Kataoka K, Matsuda K, Okano T, Yoshimura A and Kudoh S: PTEN inactivation in lung cancer cells and the effect of its recovery on treatment with epidermal growth factor receptor tyrosine kinase inhibitors. Int J Oncol 31: 1157-1163, 2007.

17. El-Mansi MT and Williams AR: Evaluation of PTEN expression in cervical adenocarcinoma by tissue microarray. Int J Gynecol Cancer 16: 1254-1260, 2006.

18. Tost J: DNA methylation: an introduction to the biology and the disease-associated changes of a promising biomarker. Methods Mol Biol 507: 3-20, 2009 .

19. Anglim PP, Alonzo TA and Laird-Offringa IA: DNA methylation-based biomarkers for early detection of non-small cell lung cancer: an update. Mol Cancer 7: 81, 2008.

20. Razin A: CpG methylation, chromatin structure and gene silencing - a three-way connection. EMBO J 17: 4905-4908, 1998.

21. Mund C, Hackanson B, Stresemann C, Lübbert M and Lyko F: Characterization of DNA demethylation effects induced by 5-aza-2'-deoxycytidine in patients with myelodysplastic syndrome. Cancer Res 65: 7086-7090, 2005. 